\title{
Fitting Form to Function: Reorganization of Faculty Roles for a New Dental Curriculum and Its Governance
}

\author{
Charlotte L. Briggs, Ph.D.; Philip A. Patston, D.Phil.; G. William Knight, D.D.S., M.S., M.S.; \\ Lea Alexander, M.A.; Nancy Norman, M.A.
}

Abstract: The College of Dentistry at the University of Illinois at Chicago has reorganized its predoctoral curriculum to better integrate biomedical, clinical, and behavioral sciences using a systems-based framework. The resulting D.M.D. curriculum features small-group discussions of patient scenarios that include orofacial, systemic, and professionalism learning objectives. Small-group learning is closely coordinated with laboratory, pre-patient care, and patient care experiences. Accordingly, the college has also reorganized its faculty roles to eliminate discipline-based silos and to better ensure program coherence. The new organizational structure is designed to improve coordination among faculty course teams that develop and administer individual courses, several units that provide curriculum resources and support services, and the curriculum committee, which is charged with governance of the curriculum as a whole. In addition, the new structure employs a system of reporting and planning relationships to ensure continuous monitoring and improvement of the curriculum. This article describes six principles that guide the new faculty roles structure, defines the various faculty roles and their coordinating relationships, presents diagrams depicting the organizational structures for curriculum governance, administration, and support, and discusses mechanisms for faculty support and continuous curriculum improvement.

Dr. Briggs was Director, Office of Dental Education and Assistant Professor, Department of Pediatric Dentistry, College of Dentistry, University of Illinois at Chicago at the time of this study and is currently Director, Teaching and Learning Support Services, Division of Research and Academic Resources, Bay Path College; Dr. Patston is Associate Professor, Department of Oral Medicine and Diagnostic Sciences, College of Dentistry, University of Illinois at Chicago; Dr. Knight is Executive Associate Dean for Academic Affairs and Associate Professor, Department of Restorative Dentistry, College of Dentistry, University of Illinois at Chicago; Ms. Alexander is Director of Academic Affairs, College of Dentistry, University of Illinois at Chicago; and Ms. Norman is Instructional Technologist, Office of Dental Education, College of Dentistry, University of Illinois at Chicago. Direct correspondence to Dr. Charlotte Briggs, Center for Teaching and Learning, Bay Path College, 588 Longmeadow St., Longmeadow, MA 01106; 413-565-1492 phone; 413-565-1781 fax; cbriggs@baypath.edu.

Keywords: dental education, dental faculty, dental curriculum, faculty development, organizational change, institutional management teams, problem-based learning, active learning, assessment

Submitted for publication 1/6/12; accepted 3/16/12

I n fall 2011, the University of Illinois at Chicago College of Dentistry implemented a new curriculum leading to a D.M.D. degree rather than to the previously awarded D.D.S. This move represents a comprehensive restructuring of the content, sequence, and instructional processes of the predoctoral program. The D.M.D. curriculum is the culmination of a seven-year process of research, planning, and implementation. ${ }^{1}$ Our restructuring process and resulting curriculum structure are consistent with published goals for reform in both North American ${ }^{1,2}$ and European dental education. ${ }^{3,4}$ In an effort to integrate and contextualize all learning in relation to patient care, the College of Dentistry replaced its traditional discipline-based courses with a systems-based framework to organize learning objectives generated by faculty content experts. In this framework, the orofacial complex is studied as a system that is analogous to other body systems, and relevant foundational knowledge from such disciplines as anatomy, physiology, histology, biochemistry, microbiology, and pathology is integrated with clinical skills including those that fall into cognitive, psychomotor, and behavioral domains. Other body systems are studied in less breadth but with increased depth as compared to the previous curriculum and as they relate to contemporary oral health care. Facultydesigned patient scenarios are discussed in small groups to integrate knowledge and skills meaningfully and memorably within the context of clinical relevance. Small groups are guided by facilitators trained in a hybrid problem-based learning approach 
that supports effective group inquiry into learning objectives that are initially undisclosed to the students while refraining from direct instruction of content. ${ }^{5}$ The new curriculum significantly advances the efforts of the college to integrate biomedical, clinical, and behavioral sciences that was begun in 2002 with the introduction of eleven comprehensive care courses. ${ }^{6}$

Due to the shift in emphasis from lectures to active, scenario-based learning, the restructured program has significantly changed the roles that faculty members play in the predoctoral curriculum and has spurred a complementary initiative to reorganize the college structures for curriculum governance, administration, and support. Scholarly research on postsecondary education emphasizes the critical influence of organizational and governance structures on institutional effectiveness. ${ }^{7,8}$ In addition, Kaufman has noted that the effective functioning of medical schools that have undergone curriculum change depends on the intentional design of their governance structures. ${ }^{9}$

The purpose of this article is to describe the restructured faculty roles in the D.M.D. curriculum at the University of Illinois at Chicago and to explain how the new role structure is designed to facilitate a shift from teaching-centered to learning-centered education, eliminating disciplinary "silos" and promoting curricular coherence. Through this account we call attention to the organizational and governance aspects of curriculum change, particularly as they relate to recent efforts to shift educational practices from a teaching paradigm to a learning paradigm and an associated trend toward an "unbundling" of the traditional faculty teaching role into a set of distributed and collaborative responsibilities. ${ }^{10-12}$ Contemporary understanding of how people learn, often referred to as constructivism, centers largely on the need for students to actively process new information in ways that either build on or restructure prior knowledge. Therefore, a consensus has emerged among learning psychologists that the role of faculty members in the learning process is not to deliver content to a passive audience but rather to design and facilitate activities to engage learners with resources and experiences that promote active inquiry and the construction of individual understanding. While the success of the learning process is measured by how closely that understanding conforms to that of faculty experts, genuine comprehension and long-term retention depend on the success of the learner's own learning processes and not merely on whether content has been delivered and memorized.
Because content expertise, instructional design, development of multimedia learning resources, and classroom facilitation draw on distinct knowledge and skills that not all faculty members possess, curriculum planning and instruction are increasingly carried out in collaborative teams of faculty members and, in some cases, instructional developers who hold staff positions. This model of instructional design and implementation differs markedly from the traditional academic arrangement of courses that are planned and delivered by an individual faculty member accountable to a single academic department with - more often than not - only minimal coordination with other courses in a program. While faculty collaboration and a greater emphasis on learning have long been goals of educational reformers, few models of comprehensive organizational restructuring at the departmental or professional school level have been documented and disseminated to support shared responsibility for developing, administering, and monitoring learning-centered educational programs.

\section{Conceptual Foundations: Six Principles}

Six principles guide the College of Dentistry's new faculty roles structure. As a whole, the principles represent our effort to design a structure that explicitly acknowledges and proactively balances competing values that are inherent in academic life and to create sustainable processes of incremental and continuous curriculum improvement.

\section{Principle 1: Student Learning Benefits from Curricular Coherence}

Curricular coherence requires attention to a variety of curriculum design elements beyond content integration alone. ${ }^{13-16}$ Coherence refers to the extent to which students comprehend the various parts of the curriculum as contributing to a meaningful whole. ${ }^{16}$ For this to occur, students must recognize connections among topics that comprise the course and program. Curricular coherence can be promoted by various means but perhaps most obviously by efforts to explicitly reference topics from one lesson or course to another. Shared program-level curricular frameworks that represent an integrative perspective can scaffold individual faculty members' efforts to 
improve coherence and may help to reinforce students' awareness of intended connections. In dental education, as in other health professions programs, traditional arrangements of discipline-based courses have tended to obscure rather than illuminate the connections among topics that faculty members believe make them relevant to dental practice. In recent years, the introduction of comprehensive care courses has represented an effort to improve coherence through horizontal integration of disciplines, often around themes such as prevention.

While curricular coherence has been a focus of reform efforts for several decades in K-12 education $^{13,14}$ and in baccalaureate majors and general education programs, ${ }^{11,15,16}$ the term has yet to enter the vocabulary of most dental educators. Dental educators have clearly made strides toward increased coherence through curricular restructuring and pedagogical reforms to achieve horizontal and vertical integration (that is, integration among disciplines and between didactic and clinical learning, respectively). However, at the University of Illinois at Chicago, we choose to emphasize the principle of curricular coherence above and beyond integration because the term "coherence" reminds us that program effectiveness must be measured not by how thoroughly we have reorganized our content but instead by how successfully our students can integrate a complex web of knowledge and apply it to a specific patient care problem. This distinction between integration and coherence exemplifies a shift from a teaching paradigm to a learning paradigm, in which the fundamental question is no longer "What are we teaching?" but rather "What are students learning?" Indeed, it is reasonable to hypothesize that expert clinical reasoning might most reliably emerge in graduates of dental programs that successfully achieve curricular coherence and might be less likely to occur in graduates of programs that provide opportunities to practice reasoning only within the logical frame and scope of knowledge of individual courses. Our own experience with comprehensive care courses illustrates the challenge of achieving coherence through content integration alone, as topics have been sequenced more meaningfully yet are still delivered in relatively self-contained modules with little or no collaboration among module coordinators to achieve conceptual linkages among discrete units of instruction.

Coherence in our new D.M.D. program is supported horizontally by replacing a disciplinebased curriculum framework with a systems-based framework. Instead of being comprised of separate courses for subjects such as anatomy, histology, and physiology, for example, the curriculum focuses on interdisciplinary topics, such as the cardiovascular and pulmonary systems or caries risk assessment and prevention, that bring together knowledge and skills from multiple subjects and show their relevance to oral health care practice. The systems framework fosters conceptual coherence by linking learning objectives among disciplines through their relationships to the various body systems, including the orofacial system, and relating learning about each system to relevant contexts in patient care. Coherence is supported vertically by deemphasizing the boundaries of academic terms in sequencing decisions in favor of a spiral structure of four successive "loops" that introduce and then revisit topics in increasing levels of complexity. Loops addressing the orofacial complex are organized around the themes of primary, secondary, and tertiary prevention (loops 1, 2, and 3) and medically complex cases requiring referral (loop 4). Loops addressing other body systems are organized around health (loop 1), disease (loop 2), facultyselected systemic diseases and conditions that influence oral health care (loop 3), and student-selected systemic diseases and conditions that influence oral health care (loop 4). Most importantly, this scheme promotes coherence by requiring collaborative planning and ongoing dialogue among the faculties of different disciplines. During each academic semester, students enroll in three systems courses (e.g., bones, joints, sinuses, and teeth; muscles and the central and peripheral nervous system; and integument and immune/hemopoiesis) and one orofacial course (e.g., primary prevention, health promotion, and introduction to general dentistry), each of which includes its own laboratory experiences that are linked by interdisciplinary patient scenarios explored in smallgroup discussions. (These course examples reflect the actual topics for D1 fall semester courses but not the actual course names, which consist merely of broad domain designations and sequential course numbers.)

This curricular framework, shown in Table 1, would be exceedingly difficult to maintain without accompanying changes to the organizational structure for curriculum administration. Consequently, we have created a D.M.D. coordinating team consisting of coordinators for the three major domains of knowledge in the curriculum: systems, orofacial, and professionalism (communication, behavior, community, ethics, evidence-based dentistry, epidemiology, and practice management). Each coordinator works 
Table 1. University of Illinois at Chicago College of Dentistry new curriculum framework to promote coherence though horizontal and vertical integration

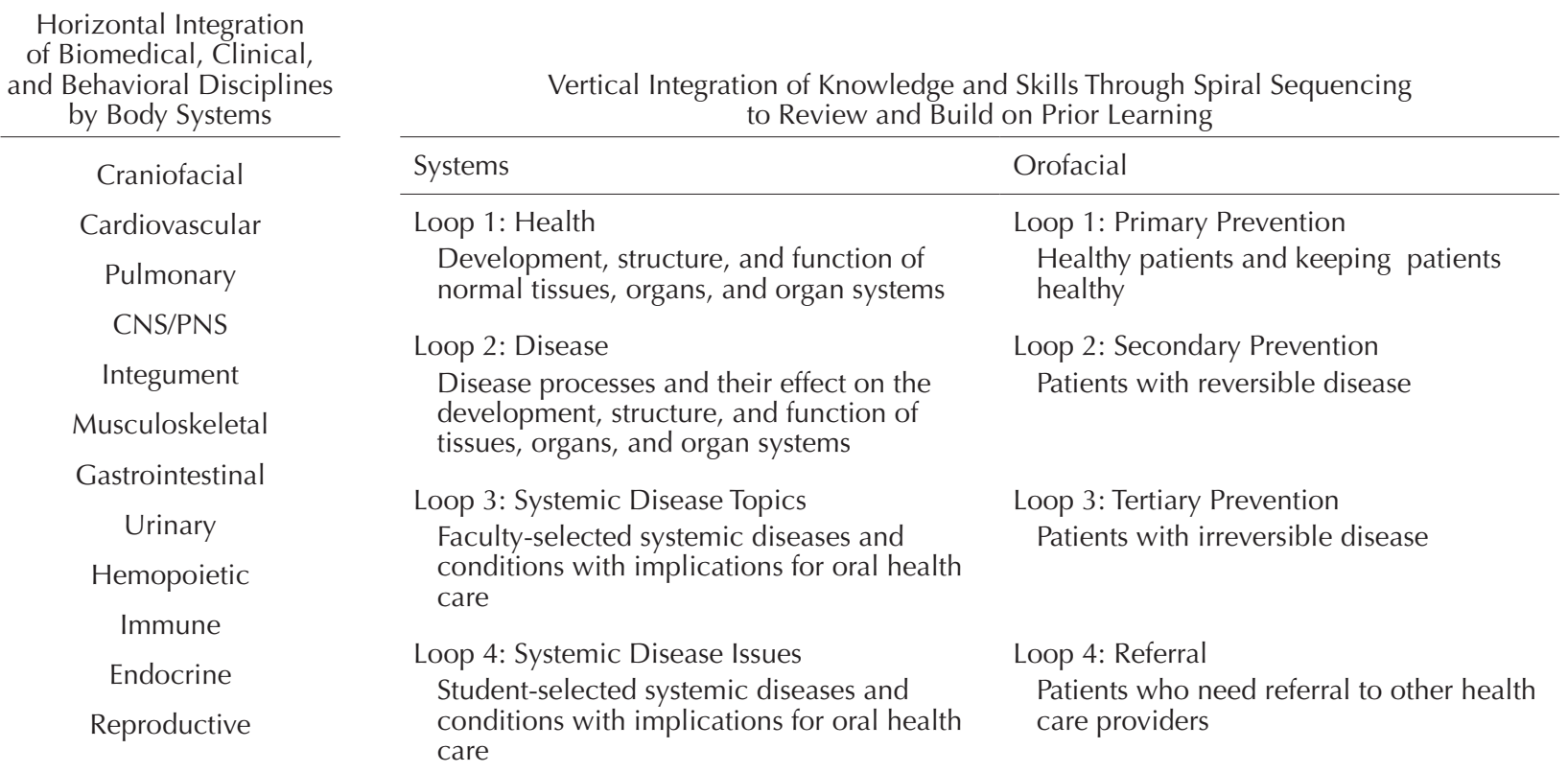

with the course directors and content experts to develop the curriculum within a given domain across courses and years of the curriculum. Content experts are typically those who have lectured on a topic in the past (e.g., immunology, pharmacology, and ethics) and who now contribute to the curriculum by developing learning objectives, instructional resources, assignments, and assessments. The D.M.D. coordinators work together to coordinate among domains. In addition, the director of small-group facilitation coordinates the scenario-writing team and the team of small-group facilitators, who collaborate with content experts from both the systems and orofacial course teams to develop and administer integrative case scenarios that help situate all student learning in the context of patient care. Because the facilitators are not content experts but rather are trained to facilitate the learning process for all three domains of the curriculum simultaneously, the director of smallgroup facilitation is located centrally in the Office of Dental Education. Likewise, a position of assessment coordinator has been established centrally within the Office of Dental Education to consult with the various teams and to serve as a liaison among them. This liaison ensures that both curricular coherence and graduating competencies are achieved through commitment to shared learning objectives structured to require that all knowledge objectives are justified as necessary to support one or more clinical skills objectives.

\section{Principle 2: Domain-Level Decisions Remain with Content Experts}

Efforts to coordinate the curriculum at the program level must optimize, not undermine, faculty discretion based on expertise. Even when disciplines are integrated and coordinated at the program level, primary responsibility for decisions regarding learning objectives and standards for student assessment within specific domains of knowledge should remain with the faculty members who are most expert in those domains. In the new faculty role structure, responsibilities for course plans, day-to-day instructional decisions, and developing and grading learning assessments remain with the course team as under the purview of the content experts who serve as course directors or instructors or whom the course team consults as needed. Instructional design, technology, and faculty development support are available to the course teams through the Office of Dental Education, and assessment support is available from the assessment coordinator but always in a consultative fashion that defers to the professional judgment of the content experts. 
Because all knowledge objectives must be justified as supporting clinical skills required for graduating competencies, content experts in foundational biomedical and behavioral sciences understand that their judgments must be informed by program goals that may differ from the goals of more traditional discipline-based courses. While coordination among faculty members from the different knowledge domains may require some measure of deference to the judgments of the clinical faculty regarding knowledge objectives, a more accurate portrayal of this relationship is one of cross-training that improves the ability of all faculty members to make judgments within their own domains of expertise to serve the program as a whole.

\section{Principle 3: Conflicts Are Mediated Through Curriculum Governance Systems}

Potential conflicts between the principle of faculty autonomy and the principle of curricular coherence are best mediated through well-designed systems of curriculum governance. In the redefined faculty role structure, we reconcile the need for faculty autonomy with the need for program coordination through a governance system that emphasizes transparency, consultation, and accountability. Plans for student learning in small groups, clinics, and laboratories and criteria for learning assessments are developed and revised at the course level in alignment with graduating competencies and program-level learning objectives. While the D.M.D. coordinating team and course directors provide operational oversight for the curriculum, the curriculum committee provides strategic oversight for the curriculum by reviewing end-of-course reports and by monitoring continuous improvement action plans that result from those reports. Alignment between course plans and program-level competencies and learning objectives is further supported by a curriculum database developed in-house that requires a nested association among these various levels of the curriculum plan.

\section{Principle 4: Curriculum Governance Systems Balance Accountability With Responsiveness}

A well-designed curriculum governance system minimizes trade-offs between accountability and responsiveness through an agile system of monitoring and reporting of targeted, quality-focused metrics. Faculty members often experience systems of curricular accountability-commonly in the form of outcomes assessment - as onerous and counterproductive to curricular flexibility and responsiveness. Both accountability and responsiveness are better achieved through frequent, targeted reporting systems than through infrequent comprehensive reporting systems. Accountability may seem more rigorous in comprehensive reporting systems, but such systems are likely to be so burdensome that they are carried out in a pro forma and superficial manner that undermines their validity. Additionally, faculty effort spent on accounting for outcomes frequently competes with effort available for responsive action. Frequent reporting that targets issues that are most likely to affect program quality, therefore, can foster a reasonable level of accountability without compromising agile responsiveness.

Effective curriculum governance employs welldefined metrics to focus attention on key indicators of intended outcomes, supplemented by open-ended inquiry to capture stakeholder insights about processes and unintended outcomes, both desirable and undesirable. ${ }^{17-23}$ The focus of both defined metrics and open-ended inquiry must be actionable information to improve the curriculum. Information is relevant if it pinpoints successes worth maintaining or disseminating or if it identifies problems that require attention, but it is actionable only if it informs decisions that realistically can be implemented within the given constraints of current or obtainable resources. ${ }^{24} \mathrm{Ef}$ fort spent collecting information for accountability purposes that is not actionable is wasteful and contributes nothing to responsiveness.

The faculty role structure reconciles the accountability needs of curriculum governance with the responsiveness needs of curriculum administration through course reports that course directors draft and submit to the D.M.D. coordinating team and the curriculum committee at the end of each course. The reports summarize the following: achievement of learning objectives, faculty and student feedback, action plans for improvement, required resources, training or faculty support, and progress on prior action plans. While requiring a summary of student learning outcomes, the reports also encourage the course teams to identify issues that are most pressing without requiring them to provide data for a laundry list of potential issues that are not of immediate concern. Thus, the reports are rather brief and intended 
to be as useful as possible by focusing on data that is of utmost concern for accountability and continuous quality improvement.

\section{Principle 5: Curriculum Governance Must Connect Curricular Needs to Resources}

Effective curriculum governance connects curricular needs to institutional resources in a strategic and timely fashion. While frequent, targeted reporting may facilitate accountability and responsiveness, it is not sufficient to guarantee these two goals unless it is part of a shared faculty-administrative governance system that includes routinized channels of communication with personnel responsible for curricular resources and faculty support. Decisions may be appropriate and actionable but left on the shelf if faculty governance lacks dedicated mechanisms to influence administrative agenda-setting and budget allocation.

The curriculum committee includes ex officio members from key offices including the executive associate dean for academic affairs (which provides staffing and resource support), the director of the Office of Academic Affairs (which provides data support and information system development), and the director of the Office of Dental Education (which provides curriculum, instruction, and educational technology support). As a result, this reporting process has a direct influence on agenda setting for key units that administer resources and provide faculty training and support.

\section{Principle 6: Faculty Development and Support Are Essential}

Curriculum and instruction is a specialized area of expertise that requires faculty development and support. Curriculum and instruction is a wellestablished specialization in undergraduate and graduate programs in education studies. While few higher education faculty members hold education degrees, a national study of U.S. faculty members and department chairs in departments that engage in continuous curriculum improvement found that members of such departments considered eight elements of curriculum planning to be domains of expertise that required their ongoing attention and study: purpose, content, learners, sequence, instructional processes, instructional resources, evaluation, and adjustment. ${ }^{25}$ This finding is in marked contrast to earlier findings that most faculty members make decisions almost exclusively about only content and sequence when developing their courses. ${ }^{26}$ Thus, the University of Illinois at Chicago College of Dentistry strives to give attention to multiple aspects of curriculum design and faculty teaching and learning development to promote the quality and ongoing improvement of its program. Additionally, while comprehensive curricular restructuring such as ours requires informed decisions in all eight of these curriculum planning elements, research on continuous planning in academic departments suggests that sustaining a culture of curriculum renewal after the implementation of a curriculum change is strongly associated with ongoing faculty development in these domains and with the existence of local communities of practice that encourage curricular innovation and experimentation, foster curriculum collaboration, and support ongoing faculty development through sharing experiences and efforts to learn together. ${ }^{11}$

The importance of faculty development and mentoring in the context of dental school faculty shortages has been discussed previously, ${ }^{27,28}$ yet scant attention has been afforded to determining how best to coordinate curriculum support structures with a dental school's curriculum administration structure. The need for improved coordination applies particularly to the part-time dental faculty members who constitute a significant portion of the educational workforce yet often are not as intimately involved with curricular issues as their full-time, tenure-track and tenured colleagues. ${ }^{29}$

To support ongoing faculty and curriculum development in a culture of continuous curriculum improvement and collaboration, the College of Dentistry has established an Office of Dental Education within its academic affairs unit. The office is led by a director who has a doctorate in education and extensive experience in developing graduate-level courses and programs for the preparation of university administrators and teaching faculty. The Office of Dental Education is staffed by faculty members who serve as director of small-group facilitation and as assessment coordinator and by an instructional technologist who holds a master's degree in learning theory and has many years' experience as an instructional developer for university faculty. The Office of Dental Education hosts an extensive lending library of books and other media devoted to education research and practice. The mission of the office is to provide expert consultation and faculty development programming and to develop collaborative linkages to other units on campus that provide resources and 
support, such as the library of the health sciences, a centralized instructional technology laboratory, and the Department of Medical Education (which offers dental faculty members the opportunity to participate in a Scholarship of Teaching Excellence Faculty Fellow Program and a Master's in Health Professions Education Program).

The faculty members who have assumed roles as small-group facilitators and scenario writers and the course directors who hold responsibility for assessment have all made efforts to develop expertise in their respective areas of responsibility. Also, the assessment coordinator and small-group facilitation coordinator, with support from the Office of Dental Education, are tasked with leading faculty development efforts in their respective areas of expertise that, over time, advance the college's collective knowledge and skills in curriculum and instruction. The director of the Office of Dental Education and the instructional technologist provide additional faculty development offerings to individuals and groups. In addition to providing "just-in-time" training and support, the Office of Dental Education continuously strives to foster faculty communities of practice by hosting informal discussions, connecting faculty members who share interests, and otherwise supporting curricular discourse and collaboration within the faculty.

The assessment coordinator organizes and facilitates an assessment seminar for course directors and other interested faculty members. The purpose of the seminar format is to foster a scholarly level of reading and discussion that exceeds the level of learning more typical of single-occasion teaching and learning workshops. In-depth faculty development is intended both to improve educational practices and to better prepare faculty members who wish to develop publishable scholarship about dental education. Equally important, the seminar format is intended to foster an informal community of practice among faculty members who share responsibility and interest in assessment.

The director of small-group facilitation is tasked with coordinating facilitator recruitment and training, as well as maintaining a system of ongoing support and development through one-on-one consultation and biweekly facilitator meetings. Facilitator meetings allow facilitators to prepare for and debrief from the patient scenarios they facilitate while providing frequent opportunities for sharing experiences and finding solutions to challenging situations in the small groups. A facilitators' discussion blog provides additional opportunity for the facilitators to learn from each others' experiences and to communicate needs for faculty development. Because facilitation skill includes a strong "craft" aspect that lends itself to learning from experience, the facilitator meetings and facilitator discussion blog are intended to provide a comfortable venue for informal sharing and to foster a culture of collaboration among the facilitators that contributes to ongoing skill building.

\section{Description and Organization of Faculty Roles}

Table 2 shows descriptions of faculty roles in the new D.M.D. curriculum. All roles except for the assessment coordinator are formally defined as parts of teams or committees, while the assessment coordinator works in close collaboration with all of the teams. The team structures foster frequent ongoing communication and collaboration within subgroups of faculty, while the D.M.D. coordinating team and assessment coordinator work to foster continuous communication and collaboration among teams. Administrative and staff roles are not included on the table but are described in the sections that follow.

Faculty roles in the new curriculum are organized around three core functions: governance, administration, and support. Figures 1, 2, and 3 include the faculty roles and relationships that are designed to address these three functions. The nexus of these three organizational structures, ensuring alignment among them, is assessment.

\section{Curriculum Governance, Administration, and Support}

Figure 1 shows the new curriculum governance structure designed to improve coordination between faculty course teams who develop and administer individual courses and the curriculum committee, which is charged with oversight and governance of the curriculum as a whole. In addition, it is designed to align budgeting and program plans within the Office of Academic Affairs with the resource needs identified by the course teams in their improvement plans. A year-round D.M.D. coordinating team comprised 
Table 2. Descriptions of faculty roles within new D.M.D. curriculum

\begin{tabular}{ll} 
Role & Description \\
\hline $\begin{array}{l}\text { Curriculum Committee } \\
\text { (CC) }\end{array}$ & $\begin{array}{l}\text { A subcommittee of the College of Dentistry Executive Committee; the chief governance body } \\
\text { providing strategic decision making and oversight for the curriculum. The CC reviews end-of- } \\
\text { course reports and monitors progress on action plans. }\end{array}$ \\
$\begin{array}{ll}\text { D.M.D. Coordinating Team } \\
\text { (DCT) }\end{array}$ & $\begin{array}{l}\text { A team comprised of coordinators for the three overarching knowledge domains of the curricu- } \\
\text { lum: systems, orofacial, and professionalism. The DCT provides operational leadership to ensure } \\
\text { that the curriculum is well coordinated horizontally among the three domains and vertically } \\
\text { through successive loops of the spiral curriculum by developing and overseeing communication } \\
\text { and decision processes that span domains and courses and that reinforce the principles of the } \\
\text { D.M.D. curriculum. Serves as a liaison between the course directors and the CC by discussing } \\
\text { end-of-course reports with the CC with the goal of coordinating evaluations and action plans at } \\
\text { the program level. }\end{array}$
\end{tabular}

Scenario Writing Team A team that develops the patient case scenarios that students discuss in small groups. The SWT (SWT) works with content experts to ensure that the scenarios are well targeted to course learning objectives and to incorporate structured learning assignments as needed. The SWT works with course directors to ensure coordinated sequencing of learning experiences and ample crossreferencing by facilitators, laboratory instructors, and instructors who lead interactive didactic sessions. The team works with small-group facilitators to ensure that scenarios are effectively constructed to foster discussion and student identification of relevant learning issues.

Assessment Coordinator A consultant to course directors and their course teams to develop assessments appropriate to course learning objectives and program competencies. Coordinates program-level assessments and reports outcomes to Curriculum Committee. Initiates faculty development opportunities to build collective faculty competence in assessment. Works with the director of academic affairs to develop information systems to monitor student achievement of learning objectives and graduating competencies and to automate collection of faculty evaluation data.

Course Teams

Teams comprised of course directors, associate course directors, content experts, and laboratory and clinic facilitators that plan and facilitate learning experiences and assess learning outcomes. Course directors and associate course directors lead planning and implementation of instruction, submit end-of-course reports to the D.M.D. Coordinating Team, and implement action plans for continuous improvement. Course directors and associate course directors rotate their roles and thus form teams that remain relatively stable in personnel over time, with additional support and coordination from the D.M.D. coordinators. Content experts determine learning objectives and assessment standards, identify or develop learning resources when needed, brief small-group facilitators, facilitate interactive didactic sessions, and monitor student learning. Some content experts are core members of course teams due to other roles they play in the team as course directors or laboratory/clinic facilitators, while others participate on an ad hoc basis as needed. Laboratory and clinic facilitators plan, coordinate, facilitate, and assess learning in anatomy and histology laboratories, pre-patient care, and patient care clinical experiences. Teams coordinate plans for learning experiences with the SWT and facilitators to maximize alignment.

Small-Group Learning Facilitation Team

Comprised of the director of small-group facilitation and the small-group facilitators. Small-group facilitators guide students in small-group learning and provide formative and summative assessment of group process skills. The team provides feedback to the Scenario Writing Team to revise scenarios. The director of small-group facilitation recruits, trains, coordinates, and supports the facilitators and, as leader of the Scenario Writing Team, provides close coordination between the facilitators and scenario writers.

of three faculty members representing orofacial, systemic, and professionalism aspects of the curriculum ensures continuity in curriculum monitoring and planning among courses and across semesters in alignment with program-level graduating competencies, learning objectives, and pedagogical principles. The D.M.D. coordinating team reports course outcomes and improvement plans to the curriculum committee, while the assessment coordinator reports outcomes of program assessments that occur outside of courses, such as an annual OSCE and D1 and D4 surveys.
Figure 2 shows the new curriculum administration structure, which emphasizes shared responsibility for learning outcomes among the systems and orofacial course teams (course directors and instructors) and the small-group learning team (director of small-group facilitation, scenario writing team, and small-group facilitators). Instructors include content experts who plan and administer preclinical, clinical, and laboratory experiences, as well as those who play a more limited role by leading a small number of interactive didactic sessions and by consulting with 


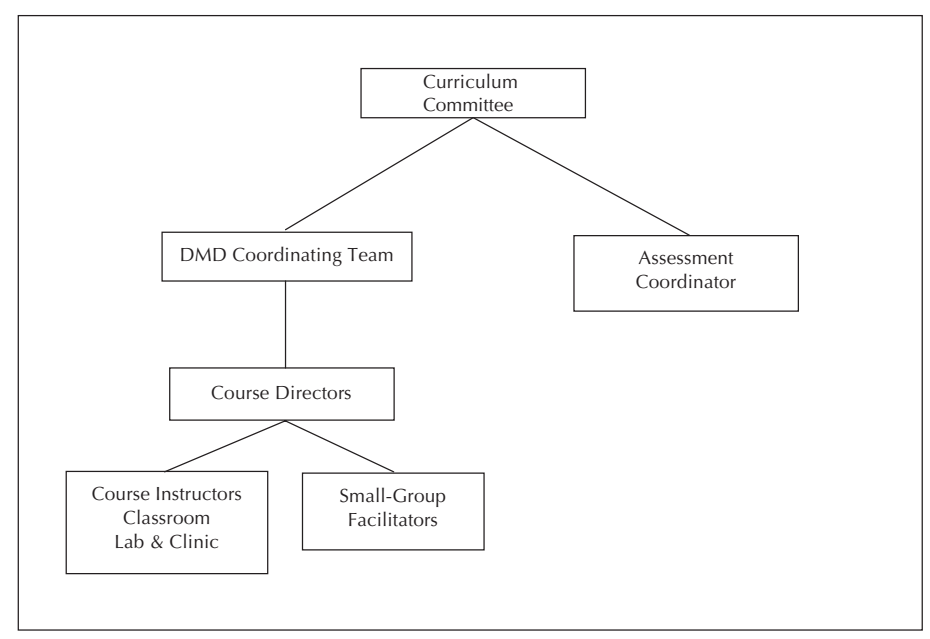

Figure 1. New curriculum governance structure

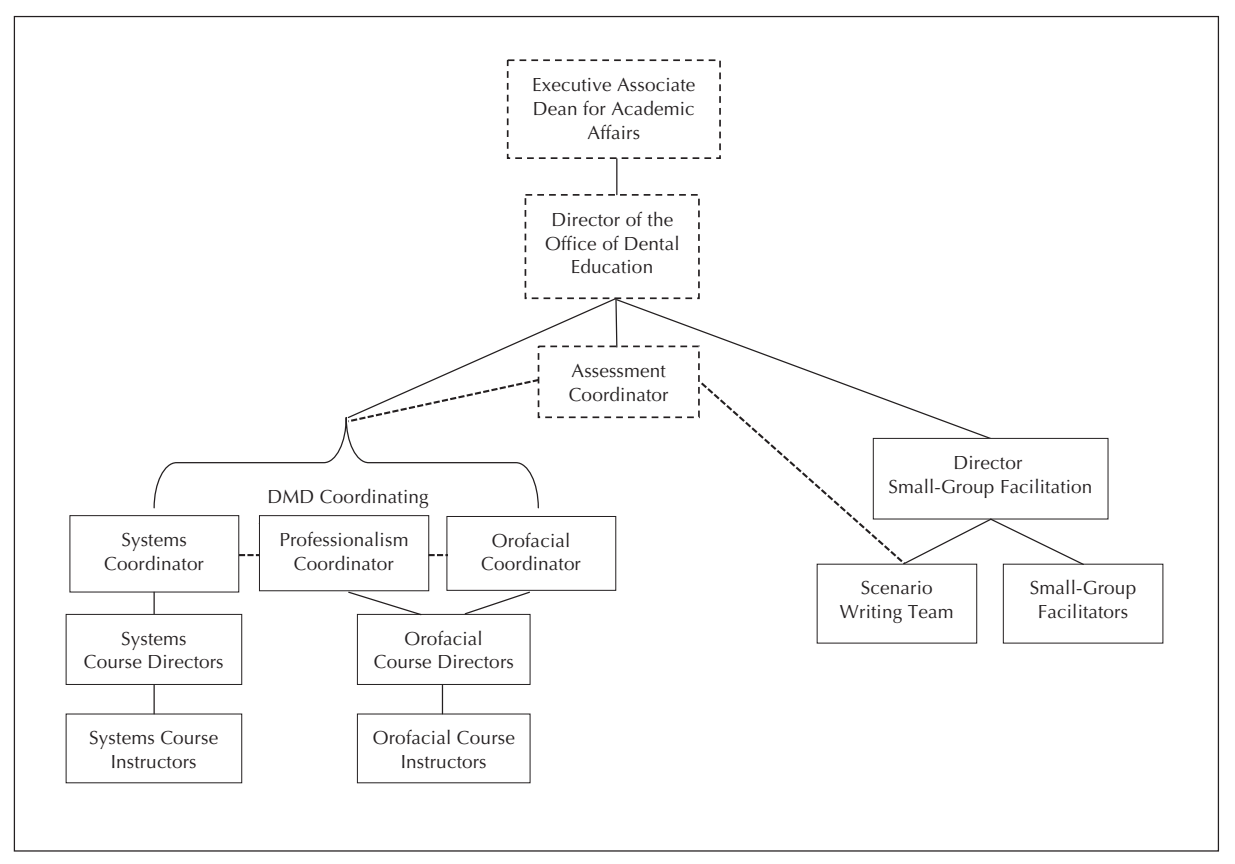

Figure 2. New curriculum administrative structure

the scenario writing team and facilitators. Content experts also develop various types of examinations to assess learning outcomes.

The positions shown in Figure 2 above the course teams and small-group learning team (D.M.D. coordinating team, assessment coordinator, director of the Office of Dental Education, and executive associate dean for academic affairs) are responsible for administrative and coordinating functions that enable the effective operation of the course teams. With the exception of the executive associate dean for academic affairs, the positioning of these roles in 


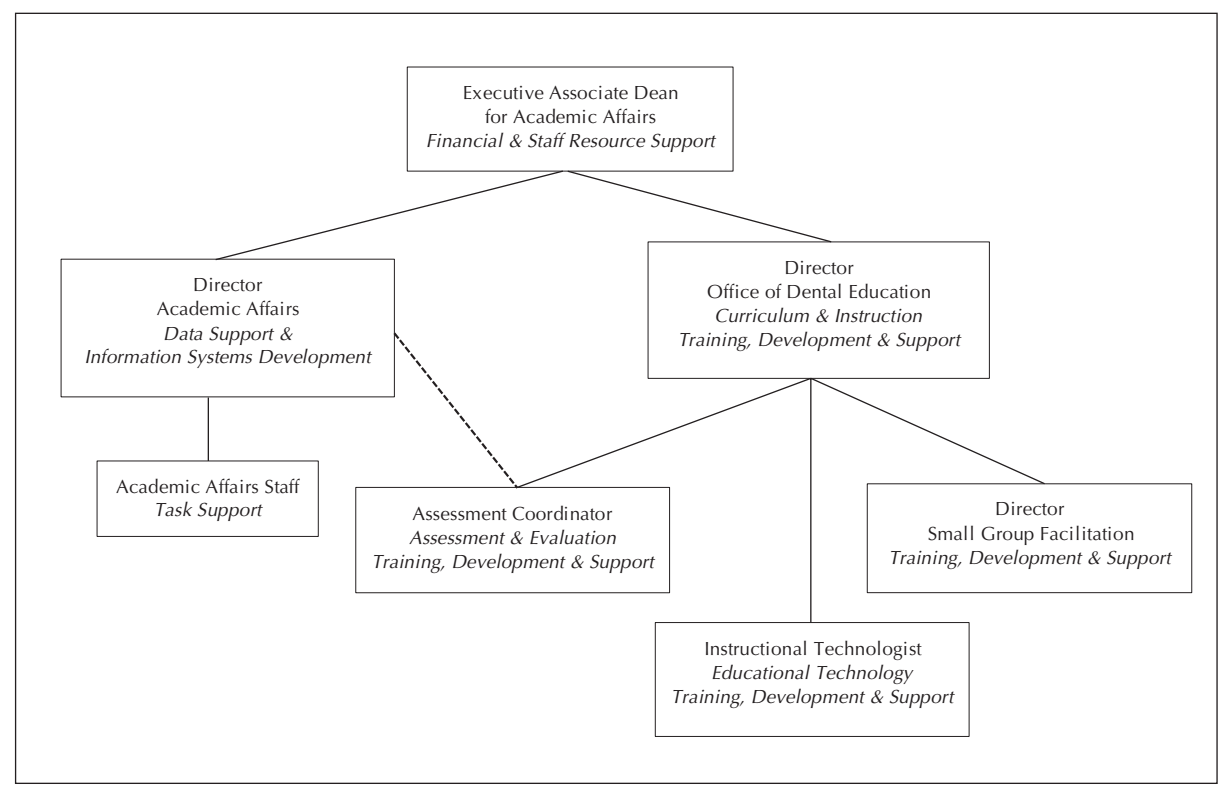

Figure 3. New curriculum support structure

the diagram is not intended to imply line authority over the course teams but rather centralized aspects of curriculum development and implementation. The D.M.D. coordinating team helps the systems and orofacial course teams to coordinate their course websites, semester schedules, and examination plans, among other things. The D.M.D. coordinators also act as liaisons between the content experts and scenario-writing team and between the predoctoral faculty and the university library and bookstore. The assessment coordinator helps to coordinate the teams' efforts to achieve shared learning objectives and to ensure coherence and intentional reinforcement of concepts among courses while avoiding unintentional gaps and redundancies. The director of the Office of Dental Education helps to identify operational process and policy issues that need attention and serves as a clearinghouse for ad hoc administrative needs that are not clearly within the purview of others. The executive associate dean for academic affairs provides coordination with the associate dean for student and diversity affairs, the associate dean for clinical affairs, the academic department heads, and the Subcommittee on Student Promotions.

Figure 3 shows the faculty and staff roles that comprise the support structures for the new curriculum. The Office of Dental Education is the clearinghouse for most faculty teaching development and support, including in the area of instructional technology. The director provides educational consultation to faculty members, department heads, and administrators regarding curriculum design and instructional practices. The instructional technologist provides in-house support for the university's learning management system (Blackboard Learn version 9), lecture capture platform (Echo360), and a wide variety of other digital media and communication tools used by faculty members in the learning process. The instructional technologist also monitors equipment maintenance and supply needs for classrooms and acts as liaison to the university's academic computing unit and the college's information technology unit, which reports to the associate dean for clinical affairs.

The Office of Dental Education also houses the director of small-group facilitation, who is responsible for training, developing, and supporting the small-group facilitators and leading the scenariowriting team. The director of the Office of Dental Education provides administrative support to the small-group facilitation process and the scenariowriting team by providing meeting support and document management assistance. Staff in the Office of Academic Affairs provide additional task support 
by, for instance, photocopying scenario materials for small-group learning discussions and entering data from evaluation forms pending implementation of a Web-based platform.

Also working under the umbrella of the Office of Dental Education is the assessment coordinator, who consults with course teams and individual faculty members concerning development and interpretation of assessments. The assessment coordinator also collaborates with the director of academic affairs to develop efficient systems of data collection and analysis for learning outcomes, course evaluations, small-group learning process evaluations, and student evaluations of small-group facilitators and instructors. All personnel within the Office of Dental Education provide faculty development programs to ensure the continued advancement of faculty teaching and learning skills.

\section{Assessment and Continuous Improvement Reporting}

As Figures 1, 2 and 3 show, the assessment coordinator plays a central role in curriculum governance, administration, and support. Table 3 summarizes these roles. More significantly, the appearance of the assessment coordinator in all three figures signifies the importance of shared objectives and metrics to meaningfully align strategic, operational, and faculty development decision making. In recent years, many colleges and universities have sought to enhance the quality and accountability of their academic programs with systems of strategic planning and assessment that mandate cycles of outcomes reporting. ${ }^{30-32}$ Unfortunately, few have invested in complementary structures for ongoing faculty development and support that are coordinated by faculty and staff with expertise in teaching, learning, and assessment, and even fewer have created organizational structures that promote genuinely ongoing dialogue and coordination among subgroups of faculty responsible for various aspects of the curriculum. It is only within the contexts of ongoing faculty development and dialogue that outcomes assessment is likely to fulfill its promise as an instrument of quality improvement and accountability. Creating those contexts, which previously had been weak or nonexistent at the college, has required thoughtful and comprehensive restructuring of faculty roles.

In addition, the reorganization of faculty roles tightly coordinates curriculum administration with curriculum governance in a cycle of continuous planning, assessment, and improvement. Course teams collect data on student outcomes and learning process variables and develop an analysis and improvement plan at the end of each course, identifying specific action items, task responsibilities, and resource needs. The D.M.D. coordinating team then reviews all course reports to identify opportunities for better coordination and cross-fertilization of ideas horizontally and vertically throughout the curriculum. Each semester, the D.M.D. coordinating team summarizes and reviews the course reports with the curriculum committee to monitor program outcomes and track progress on prior action plans.

The assessment coordinator works closely with course teams to develop assessments that are consistent with the principles of competency-based education, authentic assessment, and alignment of assessment approaches with higher-order learning objectives. The assessment coordinator also develops, analyzes, summarizes, and reports program-level assessments (such as an annual OSCE assessment, D1 end-of-year survey, and D4 exit survey) to the curriculum committee.

Perhaps most importantly, the team-based structure through which faculty members collaborate to develop and implement the curriculum promotes not only curricular coherence but also a set of rela-

Table 3. Assessment coordinator roles in curriculum governance, administration, and support

\begin{tabular}{ll} 
Curricular Area & Description of Roles \\
\hline Governance & Oversees program evaluation activities outside of individual courses. \\
Administration & $\begin{array}{l}\text { Oversees alignment of the learning objectives with course plans and assessments and also with small- } \\
\text { group learning scenarios. }\end{array}$ \\
Support & $\begin{array}{l}\text { Consults with faculty in development and analysis of assessments; collaborates with director of academic } \\
\text { affairs to develop and implement curriculum information systems. Organizes faculty development pro- } \\
\text { grams to increase faculty expertise in assessment. }\end{array}$
\end{tabular}


tionships that foster frequent informal discussion that motivates and informs continuous improvement as a sustainable part of the college's everyday culture rather than as an additional set of formal planning activities.

\section{Conclusion}

At the time this article was submitted for publication, the College of Dentistry had completed one full semester of the new curriculum. Although it is too early to report outcomes with any confidence, initial data collection from the four D1 fall courses shows student examination scores - to the extent that they are comparable - to be equal or superior to those of prior classes. Anecdotally, faculty members report more thorough and thoughtful written assignments, significantly more active participation in large class formats, and more mature communication with faculty members by individual students and the class as a whole. An end-of-term debriefing meeting of all faculty and staff members involved in the new fall courses also confirmed overwhelmingly positive views of the implementation to date. In particular, there was widespread agreement that course directors and team members have never before been as well informed about what is taking place in courses other than their own and had never before experienced such a high level of collaboration and coordination across courses and with college administrative and support offices. Faculty development, especially as it relates to facilitating small groups, developing assessments, and leading interactive didactic sessions with large groups of students, was identified as an ongoing need to prepare faculty members for new roles.

Additionally, more work must be done to acquaint faculty members and students with the new organizational structure to avoid confusion and to improve communication flows. Perhaps most significantly, the new faculty roles structure has created a need to revisit the college's promotion and tenure guidelines and to revise policies regarding teaching loads and how faculty members are assigned to various responsibilities in the curriculum. In the future, we anticipate reporting more fully on the various outcomes of our new faculty role structure and what we have learned about planning and implementing this type of organizational change.

The reorganization of faculty roles at the University of Illinois at Chicago College of Dentistry seeks to coordinate curriculum governance, admin- istration, and support through a cycle of assessment, reporting, and planning. Through this structure, the college seeks to achieve improved accountability and responsiveness through a tighter coupling between strategic and operational decision making and through more continuous faculty development and collaboration. All of these objectives serve a single purpose: to enhance the learning experience for students in ways that improve curricular coherence and maximize the clinical excellence of graduates.

In this article, we presented the organizational and governance structure that we have deployed to undergird the newly designed curriculum. While numerous calls for change in dental education have articulated desired outcomes and promising pedagogical approaches consistent with a shift from a teaching paradigm to a learning paradigm, ${ }^{33,34}$ few authors have proposed a set of potential structural changes to support such pedagogical changes or described in detail the actual structural changes that have accompanied any particular program revision. In this article, we have described the structural changes implemented at the University of Illinois at Chicago College of Dentistry to support a comprehensive revision of the predoctoral curriculum and have attempted to convey the core principles underpinning their design.

\section{REFERENCES}

1. Crawford JM, Adami G, Johnson BR, Knight GW, Knoernschild K, Obrez A, et al. Curriculum restructuring at a North American dental school: rationale for change. J Dent Educ 2007;71(4):524-31.

2. Kassebaum DK, Hendricson WD, Taft T, Haden NK. The dental curriculum at North American dental institutions in 2002-03: a survey of current structure, recent innovations, and planned changes. J Dent Educ 2004;68(9):914-31.

3. Oliver R, Kersten H, Vinkka-Puhakka H, Alpasan G, Bearn D, Cema I, et al. Curriculum structure: principles and strategy. Eur J Dent Educ 2008;12(1 Suppl):74-84.

4. Kersten HW, Vervoorn JM, Zijlstra AE, Blok BS, van Eijden TM. Development and implementation of new educational concepts in a dental curriculum. Eur J Dent Educ 2007;11(1):2-9.

5. Fincham AG, Shuler CF. The changing face of dental education: the impact of PBL. J Dent Educ 2001;65(5): 406-21.

6. Licari FW, Knight GW. Developing a group practice comprehensive care education curriculum. J Dent Educ 2003;67(12):1312-5.

7. Brown MC, ed. Organization and governance in higher education. $5^{\text {th }}$ ed. Association for the Study of Higher Education. Boston: Pearson Custom Publishing, 2000.

8. Gayle DJ, Tewarie B, White AQ. Governance in the twenty-first-century university: approaches to effective leadership and strategic management. ASHE-ERIC 
Higher Education Report 30(1). San Francisco: JosseyBass, 2003.

9. Kaufman A. Leadership and governance. Acad Med 1998;73(9 Suppl):S11-5.

10. Briggs CL. Models of curriculum governance: a research agenda. Los Angeles: Center for Higher Education Policy Analysis, 2002.

11. Briggs CL. Curriculum collaboration: a key to continuous program renewal. J Higher Educ 2007;78(6):676-711.

12. Barr RB, Tagg J. From teaching to learning: a new paradigm for undergraduate education. Change 1995;27(6):1225.

13. Ennis CD. Examining curricular coherence in an exemplary elementary school program. Res Q Exerc Sport 2008;79(1):71-84.

14. Schmidt WH, Wang HC, McKnight CC. Curriculum coherence: an examination of U.S. mathematics and science content standards from an international perspective. J Curr Stud 2005;37(5):525-59.

15. Stark JS, Lattuca LR. Shaping the college curriculum: academic plans in action. Boston: Allyn and Bacon, 1997.

16. Stark JS. On defining coherence and integrity in the curriculum. Res Higher Educ 1986;24(4):433-6.

17. Chaffee EE, Sherr LA. Quality: transforming postsecondary education. ASHE-ERIC Higher Education Report No. 3. Washington, DC: George Washington University, 1992.

18. Special issue on continuous quality improvement principles for higher education administrators. Change 1993;25(3).

19. Marchese T. TQM teaches the academy. AAHE Bulletin 1991;44(3):3-9.

20. Marchese T. AAHE and TQM: make that "CQI." AAHE Bulletin 1992;45(3):11.

21. Seymour DT. On Q: causing quality in higher education. Phoenix: Oryx Press, 1993.

22. Sherr LA, Teeter DJ, eds. Total quality management in higher education. New Directions for Institutional Research No. 71. San Francisco: Jossey-Bass, 1991.

23. Hobson R, Rolland S, Rotgans J, Schoonheim-Klein M, Best H, Chomyszyn-Gajewska M, et al. Quality assurance, benchmarking, assessment, and mutual international recognition of qualifications. Eur J Dent Educ 2008; 12(Suppl 1): 92-100.
24. Keyek-Franssen DL, Briggs CL. Ask good questions by starting with key decisions. Educause Q 2008;31(4):34-41.

25. Briggs CL, Stark JS, Rowland-Poplawski J. How do we know a "continuous planning" academic program when we see one? J Higher Educ 2003;74(4):361-85.

26. Stark JS, Lowther MA, Ryan MP, Genthon M. Faculty reflect on course planning. Res Higher Educ 1988;29(3):219-40.

27. Bagramian RA, Taichman RS, McCauley L, Green TG, Inglehart MR. Mentoring of dental and dental hygiene faculty: a case study. J Dent Educ 2011;75(3):291-9.

28. John V, Papageorge M, Jahangiri L, Wheater M, Cappelli D, Frazer R, Sohn W. Recruitment, development, and retention of dental faculty in a changing environment. J Dent Educ 2011;75(1):82-9.

29. Patston P, Holmes D, Maalhagh-Fard A, Ting K, Ziccardi VB. Maximizing the potential of part-time clinical teachers. Clin Teach 2010;7(4):247-50.

30. Peterson MW, Einarson MK, Trice AG, Nichols AR. Improving organizational and administrative support for student assessment: a review of the research literature. Stanford: Stanford University, National Center for Postsecondary Improvement, 1997.

31. Peterson MW, Hendricks LA. An addendum to improving organizational and administrative support for student assessment: a review of the research literature. Stanford: Stanford University, National Center for Postsecondary Improvement, 2002.

32. Peterson MW, Augustine $\mathrm{CH}$. External and internal influences on institutional approaches to student assessment: accountability or improvement? Res Higher Educ 2000;41(4):443-79.

33. DePaola DP. The revitalization of U.S. dental education. J Dent Educ 2008;72(2 Suppl):28-42.

34. Haden NK, Hendricson WD, Kassebaum DK, Ranney RR, Weinstein G, Anderson EL, Valachovic RW. Curriculum change in dental education, 2003-09. J Dent Educ 2010;74(5):539-57. 